\title{
Characterization of fine and carbonaceous particles emissions from pelletized biomass-coal blends combustion: Implications on residential crop residue utilization in China
}

\author{
Yue Xu ${ }^{\text {b }}$, Yan Wang ${ }^{c}$, Yingjun Chen ${ }^{\mathrm{a},{ }^{*}}$, Chongguo Tian ${ }^{\mathrm{d}}$, Yanli Feng ${ }^{\mathrm{e}}$, Jun Li $^{\mathrm{f}}$, Gan Zhang ${ }^{\mathrm{f}}$ \\ a Key Laboratory of Cities' Mitigation and Adaptation to Climate Change (China Meteorological Administration), State Key Laboratory of Pollution Control \\ and Resources Reuse, College of Environmental Science and Engineering, Tongji University, Shanghai 200092, China \\ b State Key Laboratory of Environmental Geochemistry, Institute of Geochemistry, Chinese Academy of Sciences, Guiyang 550081, China \\ ${ }^{c}$ Key Laboratory of Industrial Ecology and Environmental Engineering (MOE), School of Environmental Science and Technology, Dalian University of \\ Technology, Dalian 116024, China \\ ${ }^{\mathrm{d}}$ Key Laboratory of Coastal Environmental Processes and Ecological Remediation, Yantai Institute of Coastal Zone Research, Chinese Academy of Sciences, \\ Yantai 264003, China \\ e Institute of Environmental Pollution and Health, School of Environmental and Chemical Engineering, Shanghai University, Shanghai 200444, China \\ ${ }^{\mathrm{f}}$ State Key Laboratory of Organic Geochemistry, Guangzhou Institute of Geochemistry, Chinese Academy of Sciences, Guangzhou 510640, China
}

\section{H I G H L I G H T S}

- Emissions of $\mathrm{PM}_{2.5}$, OC and EC from biomass pellets were lower than bulk materials.

- High thermal efficient stoves reduce emissions from pelletized biofuel.

- Pelletized biomass and coal blends could significantly decrease emissions.

\section{A R T I C L E I N F O}

\section{Article history:}

Received 2 January 2016

Received in revised form

27 June 2016

Accepted 28 June 2016

Available online 29 June 2016

\section{Keywords:}

$\mathrm{PM}_{2.5}$

OC

$\mathrm{EC}$

Biomass pellets

Pelletized biomass-coal blends

\begin{abstract}
A B S T R A C T
Bulk biofuel, biomass pellets and pelletized biomass-coal blends were combusted in a typical rural conventional household stove and a high-efficiency stove. Reductions in $\mathrm{PM}_{2.5}$, organic carbon (OC) and elemental carbon (EC) emissions were evaluated by comparing emission factors (EFs) among 19 combinations of biofuel/residential stove types measured using a dilution sampling system. In the lowefficiency stove, the average EFs of $\mathrm{PM}_{2.5}$, OC, and EC of biomass pellets were $2.64 \pm 1.56,0.42 \pm 0.36$, and $0.30 \pm 0.11 \mathrm{~g} / \mathrm{kg}$, respectively, significantly lower than those burned in bulk form. $\mathrm{EF}_{\mathrm{PM} 2.5}$ and $\mathrm{EF}_{\mathrm{OC}}$ of pelletized biomass combustion in the high-efficiency stove were lower than those of the same biofuel burned in the low-efficiency stove. Furthermore, pelletized corn residue and coal blends burned in the high-efficiency stove could significantly decrease emissions. Compared with the bulk material burned in the low-efficiency stove, the reduction rates of $\mathrm{PM}_{2.5}$, OC and EC from pelletized blends in the highefficiency stove can reach $84 \%, 96 \%$ and $93 \%$, respectively. If the annually produced corn residues in 2010 had been blended with $10 \%$ anthracite coal powder and burnt as pellets, it would have reduced about $82 \%$ of $\mathrm{PM}_{2.5}, 90-96 \%$ of OC and $81-92 \%$ of EC emission in comparison with burning raw materials in conventional household stoves. Given the low cost, high health benefit and reduction effect on atmospheric pollutants, pelletized blends could be a promising alternative to fossil fuel resources or traditional bulk biofuel.
\end{abstract}

() 2016 Elsevier Ltd. All rights reserved.

\footnotetext{
* Corresponding author

E-mail address: yjchentj@tongji.edu.cn (Y. Chen).
}

\section{Introduction}

As a kind of sustainable energy source, crop residues are characterized with permanent availability, low greenhouse gas emission and low cost of recollection (Nunes et al., 2014). Crop residues 
in China are directly burnt in open fields as a waste product and in stoves for domestic heating and/or cooking, or consumed as animal feed, plant food, or industrial materials. About 54\% of annual yield of crop-straw is used as a source of rural energy (Wang and Feng, 2004). Unfortunately, it has significant contribution to the national total airborne pollutants emission, ranking as the largest contributor to $\mathrm{OC}$ emission and anthropogenic $\mathrm{PM}_{2.5}$ emission (Lei et al., 2011), the third to BC emission (Wang et al., 2012), the second largest to PAH emission (Xu et al., 2005) according to previous established emission inventories. Government and researchers have made a great effort to reduce residential biofuel emission. For example, the Chinese government implemented the National Improved Stove Program (NISP) effectively reduced indoor air pollution by replacing traditional stoves by high thermal-efficiency ones (Edwards et al., 2007; Zhang and Smith, 2005).

Many straw utilization approaches other than direct combustion have also been applied to alleviate pollution, such as biogas technology, straw gasification, straw briquette, biomass liquefaction, straw carbonization and bio-coal technology (Zeng et al., 2007). A proper processing method should consider several aspects including energy efficiency, pollutants emission, and greenhouse gas emission. Pelleting can increase heating values of biomass (Nunes et al., 2014) and reduce particle emissions. Shen et al. (2012) estimated that $95 \%, 98 \%, 98 \%, 88 \%$, and $71 \%$ reductions in the total emissions of $\mathrm{CO}, \mathrm{OC}, \mathrm{EC}, \mathrm{PM}$, and PAHs could be achieved by replacing the raw biomass fuels combusted in traditional cooking stoves with biofuel pellets burned in modern pellet burners, which made biofuel pellets an attracting approach as crop residue processing methods. However, the popularization of modern pellet burners will take years. An affordable way is to burn improved biomass pellets by present stoves.

Co-firing biomass with coal is another new promising combustion technology on industrial scale, which significantly reduces the emission of total suspended particles, $\mathrm{PAHs}, \mathrm{CO}_{2}$ and $\mathrm{NO}_{\mathrm{x}}(\mathrm{Al}-$ Naiema et al., 2015). It is logical to assume that pelletized crop residue and coal may have great potential in rural areas, although relevant study is scares in China. In this study, a large-sized dilution sampling system with particle samplers and online monitors was employed to measure EFs of $\mathrm{PM}_{2.5}$, OC and EC emission from different biofuel-stove combinations. The objective of this study was to develop emission factors of representative biofuel in domestic stoves so that we can evaluate the reduction effects of cofiring biomass-coal blends pellets in China, and screen out the relatively effective biofuel-stove combination to reduce emissions by comparing their EFs.

\section{Material and methods}

\subsection{Biofuel and stoves}

The types of biofuel were selected via investigation of typical Chinese biofuel usage. Straw of rice, wheat, corn, beans, oil-bearing crops and cotton were the major contributors to the total crop residue production, accounting for $17.5 \%, 19.4 \%, 39.1 \%, 5.4 \%, 9.3 \%$ and $2.4 \%$, respectively (Zeng et al., 2007). In some regions short of straw, wooden logs were combusted as supplementary fuels (Zeng et al., 2007). Therefore, residues of the six dominant crops and a type of woody fuel (white pine log) in rural China were tested in our series of experiments (Table 1). Given the improvement in biomass compression technology and the expansion of biomass pellets consumption in rural China, five types of pelletized biomass fuels were also included. Properties of all the target biofuels are listed in Table 1 . The moisture content of bulk materials and biomass pellets ranged from 6.9 to $8.1 \%$, and $5.2-8.2 \%$, respectively. The carbon content ranged from 38.8 to $46.6 \%$ for bulk materials, and
$36.3-40.3 \%$ for biomass pellets.

A typical rural conventional household stove (Ganchai stove, GC) and a Shengchang high-efficiency stove (SC stove) (Chen et al., 2015a) were connected to sampling system separately. GC stove is inefficient cast-iron stoves, which can burn coal, firewood, crop residues, and rod-shaped pellets of biofuel or coal. Without a chimney, GC stoves are suitable for outside burning, or indoor areas with good ventilation. SC stove (Beijing Shengchang bioenergy S\&T Co., Ltd) is efficiency improved furnace for burning honeycomb coal pellets or pellets of biomass fuels but unsuitable for incompact bulk biofuel (http://www.bj-sbst.com/). Therefore bulk crop residues, including wheat straw, rice straw, corn stalk, bean straw and cotton stalk, were not burnt in SC stove while other biofuels were burnt both in GC and SC stoves. Totally 19 combinations of biofuel/stove types were tested in our experiments.

\subsection{Sample collection and analysis}

Sampling procedures were similar to previous study (Chen et al., 2015a). The inner chamber of stove was preheated to a high temperature before sampling. Small chips of biofuel were ignited and moved into the stove containing the fuel. Biofuels were burned undisturbed with initial masses ranging from $310 \mathrm{~g}$ to $1200 \mathrm{~g}$. After biofuels added into the stove were ignited, air masses were collected for 10-60 min until combustion finished completely under natural conditions without any disturbance. A large-sized, stationary full-flow dilution tunnel and fractional sampling system described elsewhere (Chen et al., 2015a) was employed for this study. The modified experimental system has been proved to be efficient and valid to dilute smokes from household stoves (Chen et al., 2015a, 2015b). Briefly, the system is consisted of a clean air intake, smoke conducting pipe, smoke mixture ring, dilution tunnel with $3 \mathrm{~m}$ length by $30 \mathrm{~cm}$ diameter, and constant flow pump with flowrate of $12 \mathrm{~m}^{3} / \mathrm{min}$. Those parts are connected by seamless stainless-metal tunnel. The measured flue rate in the stove chimney was about $0.5 \mathrm{~m}^{3} / \mathrm{min}$, and therefore the dilution ratio was around 24 . A fractional stream of diluted smoke $(\sim 5 \%)$ is drawn to the air samplers equipped with cyclones near the end of the tunnel. The residence time of smoke before sampled was about $1.1 \mathrm{~s}$.

Through a $\mathrm{PM}_{2.5}$ cyclone, three filter samplers collected $\mathrm{PM}_{2.5}$ particles and an Athelometer (AE-42) measured online black carbon, simultaneously (Chen et al., 2015a). The air samplers collected particles onto two quartz filters and one Teflon filter at flow rate of 75,65 and $75 \mathrm{~L} / \mathrm{min}$ respectively. Filters were weighed before and after sampling to determine the $\mathrm{PM}_{2.5}$ masses. Quartz filters were baked at $450{ }^{\circ} \mathrm{C}$ for $12 \mathrm{hr}$ and Teflon filters were Soxhlet extracted by dichloromethane (DCM) solvent for $24 \mathrm{hr}$ to remove any organic pollutants on the filters. Duplicate samples were collected for some burning combination to check the reproducibility (SI).

Two popular TOA protocols, i.e., thermal optical reflection (TOR) analysis and thermal optical transmission (TOT), were adopted to measure $\mathrm{OC}$ and EC concentrations of the particle samples loaded on quartz filters. OC, EC and TC (total carbon, the sum of OC and EC) concentrations of TOR analysis were measured following IMPROVEA protocol (Atmoslytic Inc. Model 2001A, USA), while those of TOT were derived from modified NIOSH Method 5040 (Sunset Laboratory Inc., USA), separately. Detailed procedures were given elsewhere (Chen et al., 2015a). The online optical black carbon concentrations were monitored by an Aethalometer (AE-42) at a wavelength of $880 \mathrm{~nm}$ with $60 \mathrm{~s}$ intervals, which can also monitor the whole combustion processes. Emission factors were calculated following the equation $\mathrm{S}(1)$ in SI. Details on the comparison on $\mathrm{EF}_{\mathrm{S}}$ between different methods in this study are included in SI. Since the TOT (NIOSH-derived protocol) only outlines the necessary principles for operation without specifying individual temperature 
Table 1

Moisture (mass \%), and C, $\mathrm{H}, \mathrm{N}$ (dry basis mass \%) elemental analysis.

\begin{tabular}{|c|c|c|c|c|c|c|}
\hline Biofuel form & Material & Moisture & $\mathrm{C}$ & $\mathrm{H}$ & $\mathrm{N}$ & $\mathrm{S}$ \\
\hline \multirow[t]{7}{*}{ Bulk material } & Wheat straw & $7.53 \pm 0.00$ & $40.40 \pm 0.01$ & $5.78 \pm 0.00$ & $0.48 \pm 0.00$ & $0.48 \pm 0.00$ \\
\hline & Rice straw & $7.09 \pm 0.01$ & $38.77 \pm 0.49$ & $5.64 \pm 0.04$ & $0.66 \pm 0.10$ & $0.44 \pm 0.02$ \\
\hline & Corn stover & $8.14 \pm 0.00$ & $42.18 \pm 0.04$ & $6.00 \pm 0.01$ & $0.71 \pm 0.02$ & $0.45 \pm 0.03$ \\
\hline & Bean straw & $7.85 \pm 0.40$ & $43.45 \pm 0.04$ & $6.25 \pm 0.00$ & $0.78 \pm 0.02$ & $0.40 \pm 0.01$ \\
\hline & Cotton stalk & $7.86 \pm 0.01$ & $44.39 \pm 0.04$ & $6.16 \pm 0.03$ & $0.56 \pm 0.00$ & $0.37 \pm 0.01$ \\
\hline & Corn cob & $6.93 \pm 0.01$ & $43.59 \pm 0.03$ & $6.15 \pm 0.02$ & $0.47 \pm 0.00$ & $0.36 \pm 0.01$ \\
\hline & White pine & $7.01 \pm 0.00$ & $46.63 \pm 0.05$ & $6.36 \pm 0.04$ & $0.05 \pm 0.00$ & $0.31 \pm 0.01$ \\
\hline \multirow[t]{5}{*}{ Biomass pellets } & A & $8.25 \pm 0.00$ & $36.67 \pm 0.01$ & $5.43 \pm 0.00$ & $1.02 \pm 0.02$ & $0.34 \pm 0.01$ \\
\hline & $\mathrm{B}$ & $7.91 \pm 0.01$ & $40.31 \pm 0.11$ & $5.46 \pm 0.01$ & $1.01 \pm 0.02$ & $0.33 \pm 0.02$ \\
\hline & $\mathrm{C}$ & $6.83 \pm 0.00$ & $36.27 \pm 0.27$ & $5.08 \pm 0.00$ & $0.51 \pm 0.00$ & $0.28 \pm 0.01$ \\
\hline & $\mathrm{D}$ & $8.19 \pm 0.01$ & $38.72 \pm 0.13$ & $5.56 \pm 0.01$ & $1.08 \pm 0.01$ & $0.35 \pm 0.01$ \\
\hline & $\mathrm{E}$ & $5.15 \pm 0.01$ & $39.68 \pm 0.01$ & $3.67 \pm 0.01$ & $0.82 \pm 0.01$ & $0.28 \pm 0.01$ \\
\hline
\end{tabular}

Pellet A: mixture of $20 \%$ of peanut hull and $80 \%$ of corn residue.

Pellet B: peanut hull.

Pellet C: rice hull.

Pellet D: corn residue.

Pellet E: mixture of $10 \%$ of anthracite coal powder and $90 \%$ of corn residue.

at each progressive heating stage (Zhi et al., 2011), the following discussion is mainly based on TOR method, except in Fig. 1. All the statistical analyses were carried out with SPSS 13.0. Significant levels $(p)$ were set to be 0.05 .

\section{Results and discussion}

\subsection{Emissions from bulk material}

Fig. 1 compares EFs of $\mathrm{PM}_{2.5}$, EC, and OC of stove-burned crop residues and wood in China. The $\mathrm{PM}_{2.5}$ EFs of bulk crop residues in this study ranged from 5.85 to $16.4 \mathrm{~g} / \mathrm{kg}$ (dry weight), with an average of $11.3 \pm 3.75 \mathrm{~g} / \mathrm{kg}$. The results were comparable with previous values, but higher than those from Li et al. (2007, 2009) $(p<0.05)$. EFPM2.5 of fuel wood combustion was within the middle range of data documented in previous literature, lower than those of Shen et al. (2013a) and Chen et al. (2016) in field tests. $\mathrm{EF}_{\mathrm{OC}}$ and $\mathrm{EF}_{\mathrm{EC}}$ of fuel wood in the two studies were also different from other work (Fig. 1). It is believed that the burning processes in household may be much more random and difficult to be controlled compared to the lab emission tests (Chen et al., 2016), which could partly explain the large variations among the field measurements. Properties of biomass are also expected to result in variations on EFs. Among the combustion studies comparing crop residues and wood, OC and particle emissions of wood log were lower than those of crop residues $(p<0.05)$. Woody fuel has a higher lignin content and more compact fiber relative to crop waste and thus generates less OC emissions (Li et al., 2009). In contrast, EFs derived from similar biofuel burned in improved stoves under controlled conditions, such as Shen et al. (2010) and the present study, exhibited low variations. Compared with the present study, Shen et al. (2010) reported relatively higher $\mathrm{EF}_{\mathrm{EC}}$ and lower $\mathrm{EF}_{\mathrm{PM} 2.5}$. As they suggested, burning of low moisture fuels would have high combustion temperatures that are usually favorable for the formation of light absorbing particles (high BC or EC emission) (Shen et al., 2010). EFs of $\mathrm{PM}_{2.5}$ could decrease with decreased biofuel moisture content (Chen et al., 2010; Ni et al., 2015). The differences between the two studies are possibly related to the fuel low moisture $(1.41 \%-3.92 \%)$ in their study.

The ratio of EC to OC is a useful parameter to identify sources of carbonaceous aerosols (Novakov et al., 2000). In Fig. 1, EC/OC ratios in emissions from woody biofuel combustion were higher than those from crop residue combustion, except for two tests (Shen et al., 2013a; Chen et al., 2016). The average EC/OC ratios from biofuel combustion in the present study were somewhat close to the study of Shen et al. (2010), but higher than reported values in other literature $(p<0.05)$. It appears that a higher proportion of EC, but not OC, was generated while operating the improved stove with a chimney under laboratory conditions (Shen et al., 2013a). Biomass burning in high-efficiency stoves can also lead to higher EC/OC ratio (Shen et al., 2014). The two facts possible explain the relatively high ratios in the present study.

\subsection{Influence of stoves, biofuel pellets and co-firing}

With the initiation of Chinese NISP, improved stoves are recommended to meet the energy and environmental needs. However, not all the improved stoves resulted in benefits on both reducing health damaging pollutants and greenhouse gas emissions and increasing thermal efficiencies (Edwards et al., 2004). It is believed that the enhanced intense flaming conditions, higher temperature, and longer residence times in improved stoves appear to lead to higher mass fraction of $\mathrm{EC}$ even though the absolute $\mathrm{EF}_{\mathrm{EC}}$ and $\mathrm{EF}_{\mathrm{PM}}$ decrease in comparison with those from low-efficiency traditional cooking stoves (Shen et al., 2014). The $\mathrm{EF}_{\mathrm{PM} 2.5}, \mathrm{EF}_{\mathrm{EC}}$ and $\mathrm{EF}_{\mathrm{OC}}$ of the same biofuel burned in the low efficiency stove (Gan-chai stove, GC) and technically improved stove (Sheng-chang stove, SC) are compared in Fig. 2. For pelletized biomass, the $\mathrm{EF}_{\mathrm{PM} 2.5}$ and $\mathrm{EF}_{\mathrm{OC}}$ in the SC stove were statistically lower than those in the GC stove $(p<0.05)$ in this study. The $\mathrm{EC} / \mathrm{PM}_{2.5}$ ratios were generally lower than those in GC stove as well, except for pellet D. It seems that thermally high efficiency stoves can lead to lower $\mathrm{PM}_{2.5}$ and EC emission as well as mass fraction of $\mathrm{EC}$ in $\mathrm{PM}_{2.5}$ for pelletized biomass combustion (see Fig. 3).

In rural China, pelletized biomass is recommended as an energy source given its potential economic, environmental and social benefits (Hu et al., 2014). Relatively low EFs of particles from pellet combustion have been recorded because biomass pellets were characterized with high bulk density, ash content, combustion temperature and efficiency but low volatile matter content (Shen et al., 2012). Their longer residence time in stoves leads to more complete combustion, and thus reduce EC emission (Ni et al., 2014). The average EFs of $\mathrm{PM}_{2.5}$, OC, EC of biomass pellets in GC stove were $2.64 \pm 1.56,0.42 \pm 0.36$, and $0.30 \pm 0.11 \mathrm{~g} / \mathrm{kg}$, respectively. Compared with average EFs of bulk crop residue (9.83 \pm 4.67 , $1.13 \pm 0.56,0.84 \pm 0.28 \mathrm{~g} / \mathrm{kg}$, respectively) burned in the same stove, pelletizing results in a significant (Mann-Whitney $U$ test, $p<0.05$ ) decrease on EFs of $\mathrm{PM}_{2.5}$, OC and EC. Shen et al. (2012) drew a similar conclusion based on comparing the EFs of raw pine wood and corn straw with pelletized ones, even though the reported $\mathrm{EF}_{\mathrm{OC}}$ 

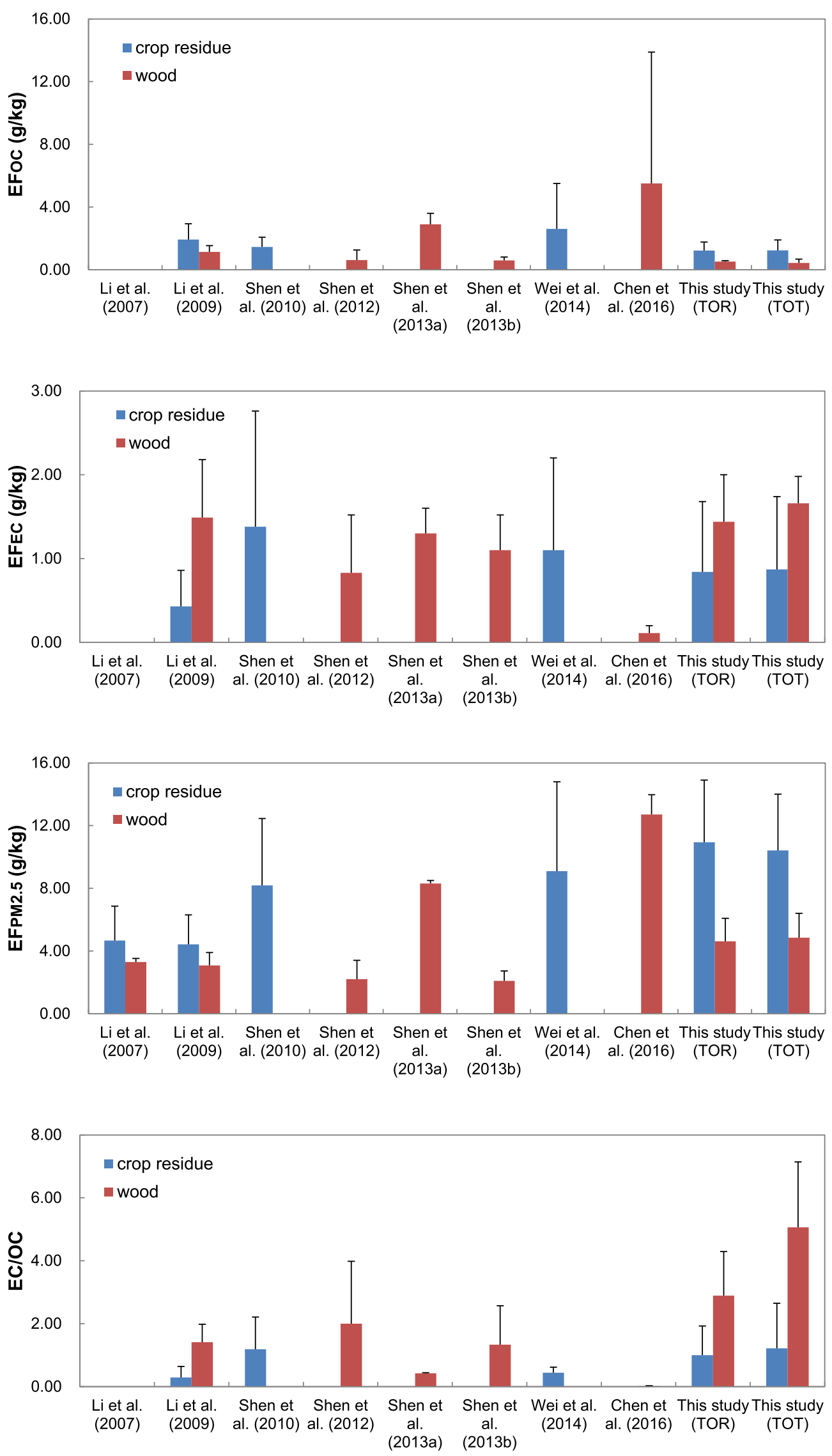

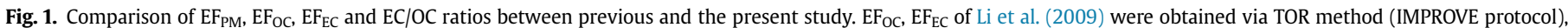

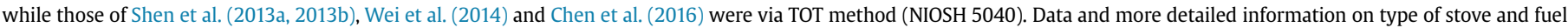
are listed in Table S1 and Table S3. 

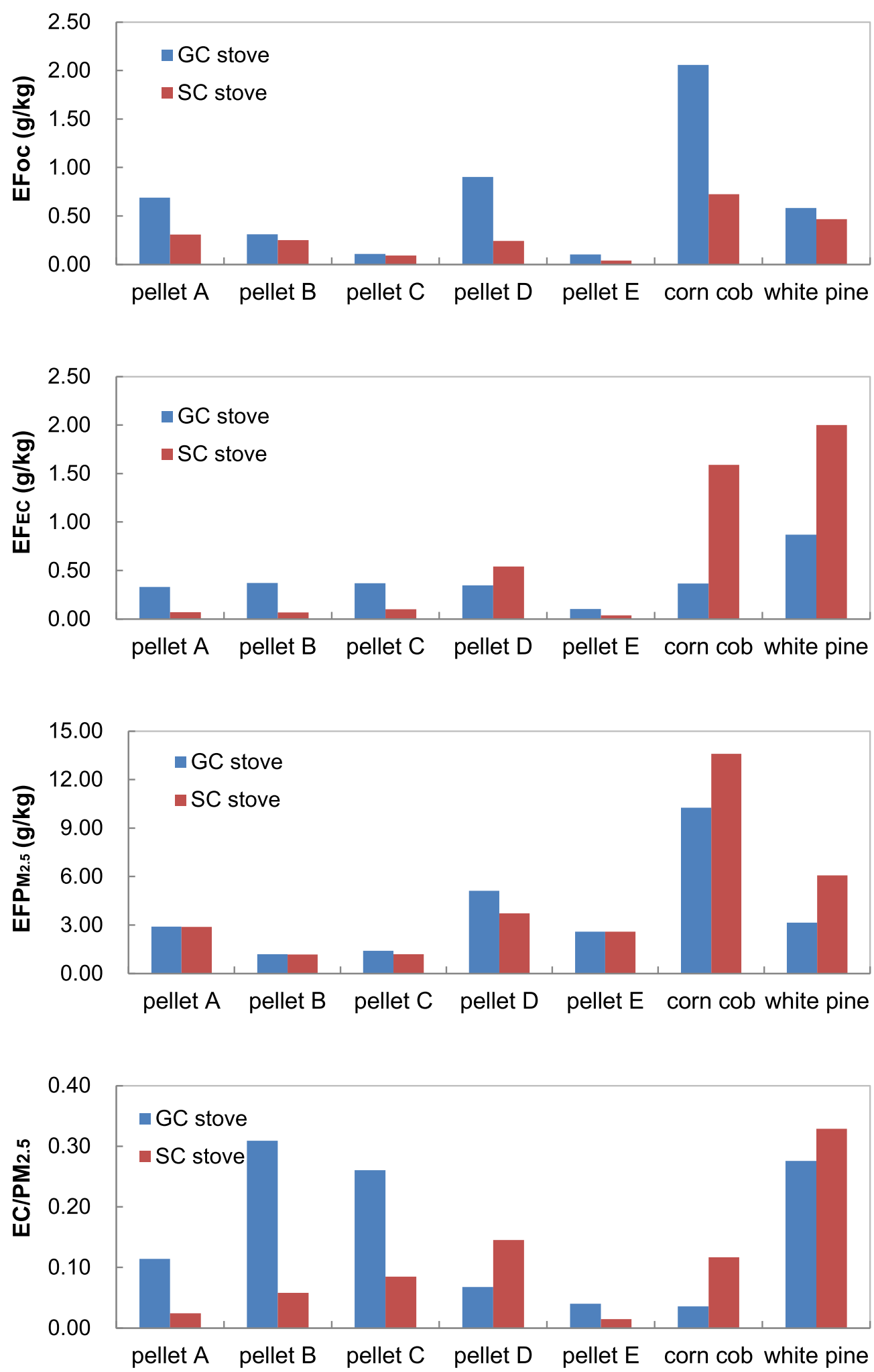

Fig. 2. Comparison of $\mathrm{EF}_{\mathrm{OC}}, \mathrm{EF}_{\mathrm{EC}}, \mathrm{EF}_{\mathrm{PM} 2.5}$ and $\mathrm{EC} / \mathrm{PM}_{2.5}$ from combustion of briquetted biofuel, corn cob and wood log in $\mathrm{GC}$ and $\mathrm{SC}$ stoves.

and $\mathrm{EF}_{\mathrm{EC}}$ were lower than the present study. Besides the differences on fuel types and analytical methods, a possible explanation on the different emissions and reduction potentials is that the applied modern pellet burner with the higher thermal efficiency was favorable for airborne pollutants reduction in the previous study.
Co-firing is another efficient means recommended in energy sector, due to its high potential for commercialization and the emission reduction of $\mathrm{CO}, \mathrm{CO}_{2}, \mathrm{SO}_{2}$ and $\mathrm{NO}_{\mathrm{x}}$ in most co-firing of biomass and coal tests (Sami et al., 2001; Johnston and van Kooten, 2015). In this study, bulk corn stover, pelletized corn stover (pellet 

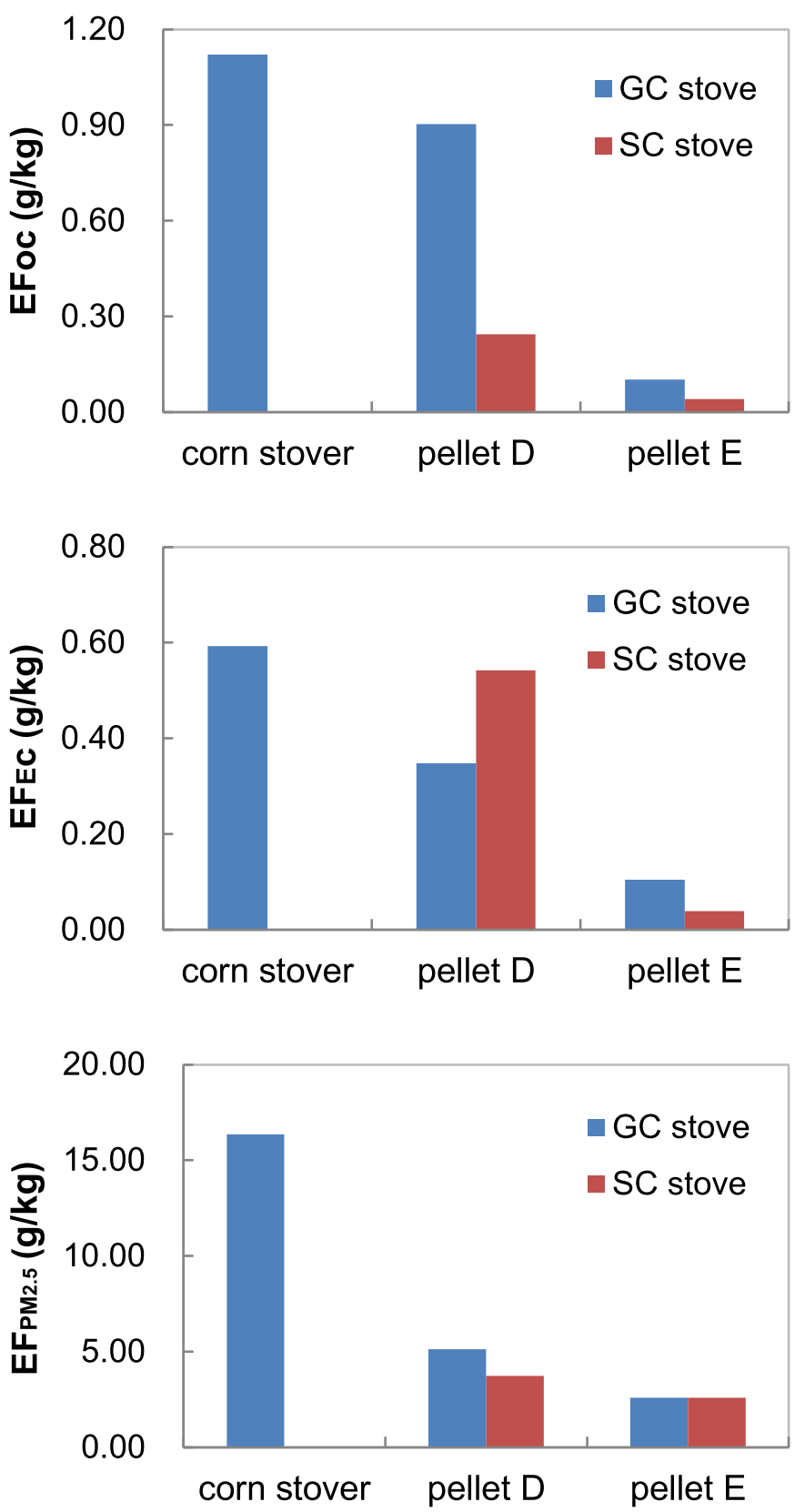

Fig. 3. Comparison of $\mathrm{EF}_{\mathrm{OC}}, \mathrm{EF}_{\mathrm{EC}}$ and $\mathrm{EF}_{\mathrm{PM} 2.5}$ from combustion of raw material, pelletized, and pelletized blends of corn stover in GC and SC stoves.

D) and pelletized coal and corn stover blends (pellet E: 10\% anthracite coal and $90 \%$ corn stover) were selected in the comparison to test the reduction effect due to the mixing of coal power into the pellets biofuels. EFs of either bulk or pelletized corn stover were in the relatively high range compared with other crop residues.
However, EFs of pellet E in SC stoves were in a low range of this study, lower than those previous reported values listed in Table S3, pelletized corn straw (Shen et al., 2012) and even close to those from anthracite combustion (Chen et al., 2015a). EFs of pellet E burned in GC stove were even lower than those of pelletized corn stover burned in SC stove. With pelleting and pellet burner, the emission of OC, EC and total particulate matter of corn straw can be reduced to $0.06,0.20$ and $2.39 \mathrm{~g} / \mathrm{kg}$ (Shen et al., 2012). In this study, adding $10 \%$ anthracite coal powder is favorable for reducing emissions of pelletized biomass. The EFs of OC, EC and $\mathrm{PM}_{2.5}$ of pellet $\mathrm{E}$ were only $11 \%, 28 \%$ and $50 \%$ of those of pellet $\mathrm{D}$ combustion in the GC stove, while were $17 \%, 7 \%$ and $69 \%$ of those of pellet D emission in the SC stove, respectively. Compared with burning bulk corn stover in the GC stove, the reduction rates of corn residues emission can reach $96 \%, 93 \%$ and $84 \%$ in the burning of pellet E in SC stove, respectively. The fractions of $\mathrm{EC}$ and $\mathrm{OC}$ in total $\mathrm{PM}_{2.5}$ reduced to $1.6 \%$ and $1.5 \%$, respectively, significantly lower than the other biofuel combustion. To date, relevant study on carbonaceous particles emitted from co-firing of pelletized biomass-coal blends is still limited. We suspect that relatively low moisture after adding coal (Table 1) may responsible for the decreased emission, since previous studies suggest that EFs will increase with increasing fuel moisture (Shen et al., 2010, 2013b). The significant decreases on carbonaceous particles and other airborne pollutants of pellet $\mathrm{E}$ in an improved stove indicates that pelletized biofuel-coal blends might be a low-cost and effective alternative to traditional biofuel in rural China, even if the current applied stoves have not been replaced by high-efficiency ones entirely.

It is worth noting that Chen et al. (2015a) reported that the mean value of EC/OC ratio was 2.48 for bituminous chunks while 0.53 for coal briquette by the same applying sampling and analytical methods. In this study, the average ratio was 1.07 (0.18-2.19), $1.12(0.23-2.22)$ and $2.89(1.49-4.29)$ for bulk crop residues, pelletized crop residues and pine wood log, respectively. Same biofuel in different form or burned in different stoves also varied significantly. The overlap between $\mathrm{EC} / \mathrm{OC}$ ratios from crop residue, woody fuel and coal reveals that it should be cautious to use the ratio to identify potential sources with the diversified energy utilizations in China.

\subsection{Implications on residential biofuel use}

As a big agricultural country, China has an abundant biomass energy resource, of which straw is the most part (Zeng et al., 2007). In 2010, the annually production of rice, wheat, corn, bean and cotton were 196, 115, 177, 19 and $5.96 \mathrm{Tg}$, respectively (NBS, 2013). Based on the documented ratios of dry residue to production (Cao et al., 2005), the corresponding crop residue production were 122 , $157,354,28.4$ and $17.9 \mathrm{Tg}$, respectively. If $54 \%$ of the crop residues (Wang and Feng, 2004) had been burned in GC stoves without pelletizing, a rough estimate of $\mathrm{PM}_{2.5}$, OC and EC emission would have been 5240, 410 and $286 \mathrm{Gg}$, respectively. Corn residue combustion would have been the major contributor, accounting for $40-60 \%$ of the total emission amount. Table 2 represented the

Table 2

The hypothetical emissions (Gg) of corn residues in different biofuel properties and stove combinations in 2010 .

\begin{tabular}{|c|c|c|c|c|c|}
\hline Biofuel stove & $\begin{array}{l}\text { Bulk corn stover } \\
\text { GC }\end{array}$ & $\begin{array}{l}\text { Pelletized corn stover } \\
\text { GC }\end{array}$ & $\begin{array}{l}\text { Pelletized corn stover } \\
\text { SC }\end{array}$ & $\begin{array}{l}\text { Pelletized blends } \\
\text { GC }\end{array}$ & $\begin{array}{l}\text { Pelletized blends } \\
\text { SC }\end{array}$ \\
\hline OC & 214 & 172 & 46.0 & 21.3 & 8.53 \\
\hline EC & 113 & 67.0 & 103 & 21.3 & 8.53 \\
\hline $\mathrm{PM}_{2.5}$ & 3130 & 983 & 713 & 551 & 551 \\
\hline
\end{tabular}


hypothetical emissions of corn residues in different biofuel properties and stove combinations. Even if adding coal increases the total amount of biofuel, the application of co-firing of pelletized corn residue and coal blends will reduce about $82 \%$ of $\mathrm{PM}_{2.5}$, 90-96\% of OC and $81-92 \%$ of EC compared with burning raw materials in the GC stove. The sales price was about $400 \mathrm{RMB} /$ ton for pelletizing corn stalk at a fully-operating $20 \mathrm{Gg} /$ a pellet fuel plant in China (Hu et al., 2014), cheaper than the price of coal. After pelletizing the $\mathrm{PM}_{2.5}$ emission from $191 \mathrm{Tg}$ corn stalk combustion decreased from $3.13 \mathrm{Tg}$ to $0.55 \mathrm{Tg}$, which means the $\mathrm{PM}_{2.5}$ reduction costs was about $2.9 \times 10^{4} \mathrm{RMB} /$ ton. Fann et al. (2012) estimated that the $\mathrm{PM}_{2.5}$-related health benefits of emission reduction were about $\$ 1.3 \times 10^{5} /$ ton to $\$ 4.5 \times 10^{5} /$ ton in US. Although the health benefits in China could be different, it still demonstrates the potential of pelletized blends on the reduction of carbonaceous particles. Besides, the approach can decrease emissions of other gases and particles like $\mathrm{CO}_{2}, \mathrm{SO}_{2}, \mathrm{NO}_{\mathrm{x}}, \mathrm{EC}$ etc, and avoid the methane leakage problem which is commonly accompanied with biogas technology (Sami et al., 2001; Johnston and van Kooten, 2015). If the energy density of biomass pellets is equivalent to medium coal as Zeng et al (2007) reported, utilization of pelletized blends as energy may not only provide a basis for airborne pollutants control, but also meets the demands for energy in rural China.

\section{Conclusion}

In this study, we measured the EFs of fine and carbonaceous particles from combustion of 19 fuel-stove combinations. Our measured EFs in the emissions from bulk crop residues combustion were in the same range of previous reported values except few studies, which could be related to the differences in experimental conditions and biomass properties. Relatively higher EC/OC ratios in this study were observed as well. Comparing the EFs of combinations of biofuel/stove types, we found that technical improved stoves may decrease $\mathrm{OC}$ but increase $\mathrm{EC}$ and $\mathrm{PM}_{2.5}$ emissions from bulk biofuel combustion. The emissions of particles from pelletized biofuel burned in high-efficiency stoves were comparable to or lower than those in low-efficiency ones. The best combination is pellet blends and high-efficiency stoves, which significantly decrease emissions of $\mathrm{PM}_{2.5}, \mathrm{OC}$ and EC and also carbonaceous fractions in $\mathrm{PM}_{2.5}$. Given the low cost, high health benefit and reduction effect on atmospheric pollutants, it may be a promising alternative to fossil fuel resources or traditional bulk biofuel. However, we should carefully test whether pellet blends increase emissions of other by-products and further verify the validity of this approach before recommendation.

\section{Acknowledge}

This work was supported by the Fundamental Research Funds for the Central Universities; National Natural Science Foundations of China (41273135, 41173098, 41373131, 41403103, 41430645 and 41473091).

\section{Appendix A. Supplementary data}

Supplementary data related to this article can be found at http:// dx.doi.org/10.1016/j.atmosenv.2016.06.073.

\section{References}

Al-Naiema, I., Estillore, A.D., Mudunkotuwa, I.A., Grassian, V.H., Stone, E.A., 2015. Impacts of co-firing biomass on emissions of particulate matter to the atmosphere. Fuel 162, 111-120.

Cao, G.L., Zhang, X.Y., Wang, D., Zheng, F.C., 2005. Inventory of emissions of pollutants from open burning crop biomass. J. Agric. Environ. Sci. 24, 800-804.
Chen, L.W.A., Verburg, P., Shackelford, A., Zhu, D., Susfalk, R., Chow, J.C., Watson, J.G. 2010. Moisture effects on carbon and nitrogen emission from burning of wildland biomass. Atmos. Chem. Phys. 10, 6617-6625.

Chen, Y., Shen, G., Liu, W., Du, W., Su, S., Duan, Y., Lin, N., Zhuo, S., Wang, X., Xing, B., Tao, S., 2016. Field measurement and estimate of gaseous and particle pollutant emissions from cooking and space heating processes in rural households, northern China. Atmos. Environ. 125, 265-271. Part A.

Chen, Y., Tian, C., Feng, Y., Zhi, G., Li, J., Zhang, G., 2015a. Measurements of emission factors of PM2.5, OC, EC, and BC for household stoves of coal combustion in China. Atmos. Environ. 109, 190-196.

Chen, Y., Zhi, G., Feng, Y., Chongguo, T., Bi, X., Li, J., Zhang, G., 2015b. Increase in polycyclic aromatic hydrocarbon (PAH) emissions due to briquetting: a challenge to the coal briquetting policy. Environ. Pollut. 204, 58-63.

Edwards, R.D., Smith, K.R., Zhang, J.F., Ma, Y.Q., 2004. Implications of changes in household stoves and fuel use in China. Energy Policy 32, 395-411.

Edwards, R.D., Li, Y., He, G., Yin, Z., Sinton, J., Peabody, J., Smith, K.R., 2007. Household CO and PM measured as part of a review of China's national improved stove Program. Indoor Air 17, 189-203.

Fann, N., Baker, K.R., Fulcher, C.M., 2012. Characterizing the PM2.5-related health benefits of emission reductions for 17 industrial, area and mobile emission sectors across the U.S. Environ. Int. 49, 141-151.

Hu, J., Lei, T., Wang, Z., Yan, X., Shi, X., Li, Z., He, X., Zhang, Q., 2014. Economic environmental and social assessment of briquette fuel from agricultural residues in China-a study on flat die briquetting using corn stalk. Energy 64 $557-566$.

Johnston, C.M.T., van Kooten, G.C., 2015. Economics of co-firing coal and biomass: an application to Western Canada. Energy Econ. 48, 7-17.

Lei, Y., Zhang, Q., He, K.B., Streets, D.G., 2011. Primary anthropogenic aerosol emission trends for China, 1990-2005. Atmos. Chem. Phys. 11, 931-954.

Li, X.H., Duan, L., Wang, S.X., Duan, J.C., Guo, X.M., Yi, H.H., Hu, J.N., Li, C., Hao, J.M., 2007. Emission characteristics of particulate matter from rural household biofuel combustion in China. Energy \& Fuels 21, 845-851.

Li, X.H., Wang, S.X., Duan, L., Hao, J.M., Nie, Y.F., 2009. Carbonaceous aerosol emissions from household biofuel combustion in China. Environ. Sci. Technol. 43, 6076-6081.

NBS, 2013. China Energy Statistical Yearbook 2012. National Bureau of Statistics China Statistics Press, Beijing, China, 2013.

Ni, H., Han, Y., Cao, J., Chen, L.W.A., Tian, J., Wang, X., Chow, J.C., Watson, J.G., Wang, Q., Wang, P., Li, H., Huang, R.-J., 2015. Emission characteristics of carbonaceous particles and trace gases from open burning of crop residues in China. Atmos. Environ. 123, 399-406. Part B.

Ni, M., Huang, J., Lu, S., Li, X., Yan, J., Cen, K., 2014. A review on black carbon emissions, worldwide and in China. Chemosphere 107, 83-93.

Novakov, T., Andreae, M.O., Gabriel, R., Kirchstetter, T.W., Mayol-Bracero, O.L., Ramanathan, V., 2000. Origin of carbonaceous aerosols over the tropical Indian Ocean: biomass burning or fossil fuels? Geophys. Res. Lett. 27, 4061-4064.

Nunes, L.J.R., Matias, J.C.O., Catalão, J.P.S., 2014. Mixed biomass pellets for therma energy production: a review of combustion models. Appl. Energy 127, 135-140.

Sami, M., Annamalai, K., Wooldridge, M., 2001. Co-firing of coal and biomass fuel blends. Prog. Energy Combust. Sci. 27, 171-214.

Shen, G., Xue, M., Chen, Y., Yang, C., Li, W., Shen, H., Huang, Y., Zhang, Y., Chen, H. Zhu, Y., Wu, H., Ding, A., Tao, S., 2014. Comparison of carbonaceous particulate matter emission factors among different solid fuels burned in residential stoves. Atmos. Environ. 89, 337-345.

Shen, G.F., Tao, S., Wei, S.Y., Chen, Y.C., Zhang, Y.Y., Shen, H.Z., Huang, Y., Zhu, D. Yuan, C.Y., Wang, H.C., Wang, Y.F., Pei, L.J., Liao, Y.L., Duan, Y.H., Wang, B., Wang, R., Lv, Y., Li, W., Wang, X.L., Zheng, X.Y., 2013a. Field measurement of emission factors of PM, EC, OC, parent, nitro-, and oxy-polycyclic aromatic hydrocarbons for residential briquette, coal cake, and wood in rural shanxi, China. Environ. Sci. Technol. 47, 2998-3005.

Shen, G., Xue, M., Wei, S., Chen, Y., Zhao, Q., Li, B., Wu, H., Tao, S., 2013b. Influence of fuel moisture, charge size, feeding rate and air ventilation conditions on the emissions of PM, OC, EC, parent PAHs, and their derivatives from residential wood combustion. J. Environ. Sci. 25, 1808-1816.

Shen, G.F., Tao, S., Wei, S.Y., Zhang, Y.Y., Wang, R., Wang, B., Li, W., Shen, H.Z Huang, Y., Chen, Y.C., Chen, H., Yang, Y.F., Wang, W., Wei, W., Wang, X.L. Liu, W.X., Wang, X.J., Simonich, S.L.M., 2012. Reductions in emissions of carbonaceous particulate matter and polycyclic aromatic hydrocarbons from combustion of biomass pellets in comparison with raw fuel burning. Environ. Sci. Technol. 46, 6409-6416.

Shen, G.F., Yang, Y.F., Wang, W., Tao, S., Zhu, C., Min, Y.J., Xue, M.A., Ding, J.N. Wang, B., Wang, R., Shen, H.Z., Li, W., Wang, X.L., Russell, A.G., 2010. Emission factors of particulate matter and elemental carbon for crop residues and coals burned in typical household stoves in China. Environ. Sci. Technol. 44, 7157-7162.

Wang, R., Tao, S., Wang, W.T., Liu, J.F., Shen, H.Z., Shen, G.F., Wang, B., Liu, X.P., Li, W. Huang, Y., Zhang, Y.Y., Lu, Y., Chen, H., Chen, Y.C., Wang, C., Zhu, D., Wang, X.L., Li, B.G., Liu, W.X., Ma, J.M., 2012. Black carbon emissions in China from 1949 to 2050. Environ. Sci. Technol. 46, 7595-7603.

Wang, X., Feng, Z., 2004. Biofuel use and its emission of noxious gases in rural China. Renew. Sustain. Energy Rev. 8, 183-192.

Wei, S., Shen, G., Zhang, Y., Xue, M., Xie, H., Lin, P., Chen, Y., Wang, X., Tao, S., 2014 Field measurement on the emissions of PM, OC, EC and PAHs from indoor crop straw burning in rural China. Environ. Pollut. 184, 18-24.

Xu, S., Liu, W., Tao, S., 2005. Emission of polycyclic aromatic hydrocarbons in China 
Environ. Sci. Technol. 40, 702-708

Zeng, X.Y., Ma, Y.T., Ma, L.R., 2007. Utilization of straw in biomass energy in China Renew. Sustain. Energy Rev. 11, 976-987.

Zhang, J., Smith, K.R., 2005. Indoor air pollution from household fuel combustion in China: a review. In: The 10th International Conference on Indoor Air Quality and Climate, Beijing, 4-9, pp. 8-10.

Zhi, G.R., Chen, YJ., Sun, J.Y. Chen, L.G., Tian, WJ., Duan, J.C., Zhang, G., Chai, F.H., Sheng, G.Y., Fu, J.M., 2011. Harmonizing aerosol carbon measurements between two condventional thermal/optical analysis methods. Environ. Sci. Technol. 45, 2902-2908 